\title{
New self-assembled layers composed with gold nanoparticles, cysteamine and dihydrolipoic acid deposited on bare gold template for highly sensitive and selective simultaneous sensing of dopamine in the presence of interfering ascorbic and uric acids
}

\author{
Teresa Luczak ${ }^{1} \cdot$ Malgorzata Osińska $^{2}$
}

Received: 1 August 2016 /Revised: 22 September 2016 / Accepted: 27 September 2016/Published online: 13 October 2016

(C) The Author(s) 2016. This article is published with open access at Springerlink.com

\begin{abstract}
A gold bare template modified with self-assembled layers (SAMs) composed of gold nanoparticles and organic Scontaining compound: cysteamine and dihydrolipoic acid were prepared. The electrode with SAMs endowed with gold nanoparticles gave a high catalytic effect for dopamine electrooxidation alone and in the presence of biogenic interfering compounds: ascorbic acid and uric acid in solution at $\mathrm{pH}$ 7. For this novel sensor, a linear relationship between the current response of dopamine at the potential of peak maximum $\left(j_{\mathrm{p}}\right)$ and the concentration of this compound in solution $\left(c_{\mathrm{DA}}\right)$ was found over the range $0.1 \mu \mathrm{M}$ to $0.85 \mathrm{mM}$ with the detection limit of $0.023 \mu \mathrm{M}$.
\end{abstract}

Keywords Self-assembled layer $\cdot$ Electrode material $\cdot$ Gold · Gold nanoparticles $\cdot$ Dopamine $\cdot$ Interfering compounds

\section{Introduction}

Dopamine (DA) belongs to catecholamine neurotransmittersa biologically important group of compounds which are mediators in transmitting messages between neurons [1, 2]. It is widely distributed in the mammalian brain. Dopamine plays an essential role in the functioning of the central nervous, renal, hormonal and cardiovascular systems. Abnormal

Teresa Łuczak

telucz@amu.edu.pl

1 Faculty of Chemistry, Adam Mickiewicz University in Poznań, Umultowska 89 b, 61-614 Poznań, Poland

2 Faculty of Chemical Technology, Institute of Chemistry and Technical Electrochemistry, Poznań University of Technology, Berdychowo 4, 60-965 Poznań, Poland dopamine level is related, among others, to the Parkinson's and Alzheimer's diseases, Tourett'e syndrome, schizophrenia as well as pituitary tumours $[3,4]$. Therefore, the development of a simple and rapid method for dopamine detection and determination is an important task of current neurochemistry. The interest in the development of such a method has resulted in a large number of reports published in the last decades. Among others, the methods such as chromatography, spectrophotometry, colorimetry and fluorescence [5-10] have been used for dopamine determination. However, dopamine is easily oxidized; thus, the electrochemical methods have been more suitable for its studies. The main interests have been paid to finding new catalytic electrode materials and use them for dopamine oxidation. The new materials should eliminate poisoning of the electrode surface with dopamine oxidation products; moreover, they should allow separation of the voltammetric signal of dopamine from those of ascorbic acid (AA) and uric acid (UA) coexisting in natural samples and electrooxidized in almost the same potential range on bare carbon or gold electrodes [11-14].

Nevertheless, over the last decades, it has been experimentally proved that in many cases, some electrochemical processes occur more effectively when modified electrodes are used, instead of pure unmodified ones. Consequently, various chemically and/or electrochemically modified electrode materials have been prepared and investigated taking into account their structural properties and the voltammetric behaviour upon the dopamine electrooxidation. A non-enzymatic amperometric sensor was developed based on the graphite electrode modified with functionalized graphene [15], and multiwalled carbon nanotubes were fabricated on oxidized porous silicon for the oxidation of dopamine [16]. A selective determination of dopamine in the presence of ascorbic acid was obtained at the gold nanoparticles deposited both on glassy carbon and gold electrodes [14, 17-20]. Simultaneous voltammetric 
detection of dopamine and uric acid in the presence of high concentration of ascorbic acid has been studied using multiwalled carbon nanotubes with methylene blue composite film-modified electrode [21] and on poly(caffeic acid)-modified glassy carbon electrode [22]. Moreover, poly(2-amino5-(4-pyridinyl)-1, 3, 4-thiadiazole) film-modified glassy carbon electrode for the simultaneous determinations of dopamine and uric acid has been used [23]. Fabrication of poly(orthanilic acid)-multiwalled carbon nanotube composite [24] and Nafion/CdSe/self-doped polyaniline composite [25] film-modified glassy carbon electrodes and their use for the simultaneous determination of uric acid and dopamine in the presence of ascorbic acid has been presented in literature as well. Dopamine electrooxidation in the presence of ascorbic acid has been studied also at Nafion-ruthenium oxide-modified glassy carbon electrode [26]. Dopamine detection in the presence of ascorbic acid was performed also by using a gold surface covered with overoxidized dopamine [27] as well as by polyaniline films [28]. It is worth noting that for dopamine oxidation in the presence of ascorbic acid, much attention has been paid to the analytical applicability of carbon or gold electrodes covered with spontaneously formed selfassembled layers (SAMs). For example, glassy carbon electrodes modified with mixed covalent monolayers of choline, glycine and glutamic acid have been used for the determination of dopamine [29]. A promotion of the dopamine oxidation was achieved after deposition of the quercetin [30], sulfonated $\beta$-cyclodextrin self-assembled layer $[31,32]$ and aliphatic thiocarboxylic acid [33-37] as well as by the composite 11-mercaptoundecanoic acid-polyethylene glycol SAM layer [38] on gold electrodes. The application of 2mercaptoethanesulfonate [39], 4-aminothiophenol [40] and triazole [41] SAM layers for simultaneous determination of dopamine and interferents like ascorbic acid or uric acid has also been considered. It has been proved that S-containing organic compounds facilitate the electron transfer in the redox reaction occurring at the electrode-solution interface. Nevertheless, they effectively protect the metal surface against adsorption of reaction products poisonous for the electrode surface [42]. As proved, the use of nanoparticles of noble metals can bring a much higher catalytic effect for processes occurring at modified electrodes when compared to those occurring at unmodified ones [14, 19, 35, 37, 43, 44].

In the study presented here, the voltammetric performance of gold modified with dihydrolipoic acid (DHLA), cysteamine (CA) and the gold nanoparticle (Au-NPs) layers was studied for electrochemical sensing of dopamine alone and in the presence of ascorbic acid and uric acid in aqueous solution, $\mathrm{pH}$ 7. The self-assembled layers were deposited on the bare gold template (labelled as $\mathrm{Au}$ ). The choice of dihydrolipoic acid was dictated by a stronger affinity of this compound towards gold and higher extent of dissociation of its carboxyl groups [45] as compared to those of the previously studied S- containing alkane acids $[35,37]$. A comparison with the results obtained on the bare gold electrode was made. Till now, literature has not provided evidence of electrocatalytic oxidation and detection of dopamine on materials composed of dihydrolipoic acid, cysteamine and gold nanoparticles.

\section{Experimental}

\section{Apparatus}

Electrochemical measurements were performed using an Autolab potentiostat/galvanostat analyser (Eco Chemie, The Nederland) in a conventional three-compartment cell. The $\mathrm{pH}$ of the solutions was measured using a $\mathrm{pH}$ meter (ModelULAB 2002, TELE-ECO-PROJECT, Poland). The reflection-absorption spectra were obtained in an $\mathrm{N}_{2}$ atmosphere on a Brucker $66 \mathrm{v} / \mathrm{S}$ FT-IR spectrometer with an FT80 grazing angle infrared reflection accessory and a liquid $\mathrm{N}_{2}$ cooled TGS detector. Typically, 2000 scans with a $2 \mathrm{~cm}^{-1}$ resolution were taken. Additionally, for comparison, the transmission FT-IR spectrum of the respective substrate was recorded on the same spectrometer. The transmission electron microscopy (TEM) image was obtained using a JEM-1200 EX2 (Japan) instrument, operating at $200 \mathrm{kV}$ after drying the gold colloidal solution covered with the foil reinforced with carbon. The scanning electron microscopy (SEM) analysis for observing the surface morphology were carried out using a Hitachi S-3400 N instrument (Japan) at the acceleration voltage of $10 \mathrm{kV}$. The UV-Vis spectra were taken using a Cecil instrument (CE 2020, Chemnist, Austria).

\section{Reagents}

All solutions were prepared using Millipore Milli-Q-water and with the mentioned chemicals of the purity given in brackets. The chemicals were used as received without further purification. $\mathrm{NaOH}(99 \%), \mathrm{NaH}_{2} \mathrm{PO}_{4}(99.99 \%)$ and $\mathrm{K}_{2} \mathrm{HPO}_{4}$ $(99.99 \%)$; trisodium citrate $(99 \%)$; acetone $(99.50 \%)$; $\mathrm{H}_{2} \mathrm{SO}_{4}$ (96\% extra pure); $30 \% \mathrm{H}_{2} \mathrm{O}_{2}$ (min. $29 \%$, max. $33 \%)$ and $\mathrm{C}_{2} \mathrm{H}_{5} \mathrm{OH}(99.9 \%)$ were purchased from POCh (Gliwice, Poland), whereas $( \pm$ )dihydrolipoic acid $(99.9 \%)$, cysteamine ( $\geq 99 \%$ ), auric acid $\left(\mathrm{HAuCl}_{4}\right)(99.999 \%)$, dopamine $(99.9 \%)$, ascorbic acid (99.9\%) and uric acid (99.9\%) were from Sigma-Aldrich. The gold colloidal solution ( $\mathrm{Au}$ sol) was prepared according to the Turkevich procedure [46]: $1.5 \mathrm{~cm}^{3}$ of $0.60 \% \mathrm{HAuCl}_{4}$ was added to $100 \mathrm{~cm}^{3}$ of water and heated until boiling. Then, $5 \mathrm{~cm}^{3}$ of $1 \%$ trisodium citrate was added to the boiling solution upon stirring. A typical red wine colour was observed after a few minutes. The gold sol was stored in a dark glass at $4{ }^{\circ} \mathrm{C}$. As a supporting electrolyte solution, a phosphate buffer of $60 \mathrm{mM}, \mathrm{pH} 7$, was used. All the solutions investigated were deaerated by highly 
pure argon (99.998\%) before measurements performed at room temperature.

\section{Electrodes}

In the study presented here, the working electrode of $0.065 \mathrm{~cm}^{2}$ geometric areas was either the bare gold (Polish State Mint) electrode (marked as Au electrode) or the prepared modified gold electrodes. As a counter electrode, a gold sheet was used, whereas a saturated calomel electrode (SCE) was used as a reference electrode in all measurements. Prior to use, the bare gold electrode was cleaned with alumina slurry of successively decreasing grades to $0.05 \mu \mathrm{m}$ on polishing cloths and subsequently rinsed with water, acetone and again with water. Then, the electrode was electrochemically activated by scanning the electrode potential $\left(v=d E / d t=0.1 \mathrm{Vs}^{-1}\right)$ between the onset of hydrogen and oxygen evolution (in the potential range between $E=-0.90 \mathrm{~V}$ and $E=0.45 \mathrm{~V}$ versus SCE) in the supporting electrolyte solution (the phosphate buffer, $60 \mathrm{mM}, \mathrm{pH} 7$ ), until a stable voltammogram (acronyms: $\mathrm{CV}, j-E$ curve) and reproducible values of the double layer capacitance were obtained. This procedure avoids structural changes on the gold electrode surface [47-49].

The modification process of the bare gold electrode was divided into three steps. At first, the self-assembled layer (SAM) of dihydrolipoic acid was prepared by immersion of the activated $\mathrm{Au}$ template in a $10 \mathrm{mM}$ ethanolic solution of this acid, for $6 \mathrm{~h}$. The obtained electrode Au/DHLA was washed with water, acetone and again with water and dried in argon stream. In the second step of modification, the $\mathrm{Au} /$ DHLA template was immersed in a $0.2 \mathrm{mM}$ solution of cysteamine for $2 \mathrm{~h}$. The obtained Au/DHLA/CA electrode was washed and dried in the same way as in the first step. In the third step of modification, in order to immobilize of the gold nanoparticles, the obtained Au/DHLA/CA SAM template was dipped in the gold sol solution at $4{ }^{\circ} \mathrm{C}$ for $16 \mathrm{~h}$. After that, the procedure of washing and drying was repeated. The $\mathrm{Au} /$ DHLA/CA/Au-NPs electrode prepared according to the above-described three-stage process was ready to use in electrochemical measurements. The following electrodes were obtained according to the following scheme:

$\mathrm{Au} /$ DHLA electrode: $[\mathrm{Au} \rightarrow$ DHLA acid (6 h)]; $\mathrm{Au} / \mathrm{DHLA} / \mathrm{CA}$ electrode: $[\mathrm{Au} \rightarrow$ DHLA acid $(6 \mathrm{~h}) \rightarrow$ CA (2 h)];

$\mathrm{Au} / \mathrm{DHLA} / \mathrm{CA} / \mathrm{Au}-\mathrm{NPs}$ electrode: $[\mathrm{Au} \rightarrow$ DHLA acid $(6 \mathrm{~h}) \rightarrow \mathrm{CA}(2 \mathrm{~h}) \rightarrow$ sol Au $(16 \mathrm{~h})]$.

Preliminary studies have shown that the highest catalytic effect was obtained for $\mathrm{Au} / \mathrm{DHL} / \mathrm{CA} / \mathrm{Au}-\mathrm{NPs}$ electrode (this electrode is henceforth referred to as $\mathrm{Au} / \mathrm{Au}$ -
NPs) and therefore, in the next section, the results obtained only for the $\mathrm{Au} / \mathrm{Au}-\mathrm{NPs}$ electrode are presented. As a result of the gold electrode modification, the roughness factor $(r f)$ was changed. It was calculated as the ratio of the electrochemical surface area of the electrode to its geometrical area. The roughness factors of the surface of the used electrodes were estimated assuming that the charge of $0.400 \mathrm{mC} \mathrm{cm}^{-2}$ [50] is required for the reduction of a monolayer of oxygen, which was chemisorbed onto a given gold surface during the positive potential sweep up to the potential of the characteristic current minimum that appears on the CVs after the gold oxidation peak current, i.e. prior to the oxygen evolution. Taking into account the charge obtained by integration of the respective cathodic peaks in the CVs of the electrodes used, the roughness factors of the used modified and unmodified gold electrodes were estimated as 2.9 and 1.6, respectively.

To characterize the repeatability of the bare gold electrode and the used modified gold electrode, repetitive measurements were carried out in a solution containing $0.5 \mathrm{mM}$ dopamine. The R.S.D. (\%) of the voltammetric responses for 10 successive determinations on the $\mathrm{Au}$ and $\mathrm{Au} / \mathrm{Au}-\mathrm{NPs}$ electrodes were 3 and $4 \%$, respectively. Moreover, the stability of the modified electrode was verified by measuring its voltammetric response in the solution containing $0.5 \mathrm{mM}$ dopamine from day to day for 1 month. For comparison, the same experiment was made with the unmodified Au electrode. After each daily test of stability, the electrodes were washed with water, dried in the argon stream and stored in empty glass tubes. In 4 weeks, the voltammetric responses for the $0.5 \mathrm{mM}$ dopamine oxidation decreased by about 6 and $4 \%$ of their initial responses for the $\mathrm{Au}$ and $\mathrm{Au} / \mathrm{Au}-\mathrm{NPs}$ electrodes, respectively. At the end of all series of measurements, in order to recover the Au bare electrodes, the self-assembled layers were removed from the modified gold templates by dipping them in a Piranha solution $\left(96 \% \mathrm{H}_{2} \mathrm{SO}_{4}+30 \% \mathrm{H}_{2} \mathrm{O}_{2}\right.$ at the volume ratio 3:1) and the above-described procedure of polishing, activation and modification of the bare gold electrode had to be repeated.

\section{Sample preparation}

In order to test the practical application of the newly prepared voltammetric sensor, samples with the mixtures of dopamine, ascorbic acid and uric acid were analysed. Dopamine hydrochloride $\left(2 \mathrm{~cm}^{3}\right)$ of the injection solution (containing $10 \mathrm{mg}$ dopamine per $1 \mathrm{~cm}^{3}$ ) was diluted to $0.1 \mathrm{dm}^{3}$ with deionized water. This solution $\left(0.1 \mathrm{~cm}^{3}\right), 1 \mathrm{~cm}^{3}$ of standard solution of ascorbic acid $(5 \mathrm{mM})$ and $1 \mathrm{~cm}^{3}$ of standard solution of uric acid $(5 \mathrm{mM})$ were putted into a $10 \mathrm{~cm}^{3}$ volumetric flask and made up to volume with $60 \mathrm{mM}$ phosphate buffer solution, pH 7. 


\section{Results and discussion}

\section{Properties of the gold modified electrode surface}

From literature, it is known that the self-assembling layer at the template surfaces may be achieved in two ways $[43,51]$. One of them consists in forming the SAM layer using compounds with atoms characterized by high affinity to the modified template. When the atoms of the modifying compounds get in contact with those from the modified template, strong covalent bonds are developed between them. The second way for attaching modifying compounds to the modified template may be realized by direct dipping of the template into a solution with the modifying compounds. In this case, no binding molecules are used; the SAM layer is formed making use of the electrostatic, hydrogen or van der Waals' interactions. There is no doubt that the first method has an advantage over the second one because the strength of the covalent bond exceeds the strength of the other above mentioned interactions $[35,40]$.

In this study, the high affinity of sulphur atoms to gold atoms was employed. The gold template was modified with gold nanoparticles and both dihydrolipoic acid and cysteamine as the binding molecules to this template. The transmission FT-IR spectrum of the liquid dihydrolipoic acid (spectrum 1 in Fig. 1a) is compared with the infrared reflection spectrum of the Au surface with the adsorbed molecules of this acid (spectrum 2 in Fig. 1a). The FT-IR spectra give clear conjecture of the formation of the adsorbate on the Au surface as the band, in the region of $2600-2550 \mathrm{~cm}^{-1}$, assigned to the $\mathrm{S}-\mathrm{H}$ stretching vibrations disappears. The absence of this band in spectrum 2 (Fig. 1a) demonstrates that with the formation of adsorbate, the $\mathrm{S}-\mathrm{H}$ bonds are broken and the $\mathrm{S}$ atoms are directly bonded with the Au surface atoms. This result is consistent with the previously reported proton abstraction from alkanethiols adsorbed on $\mathrm{Au}$ [52-55].

The earlier [17, 35, 37, 44, 56] and present studies have shown that the gold sol obtained by the Turkevich method [46] used in this work contains gold nanoparticles of the average diameter of about $16 \mathrm{~nm}$, as evaluated from the transmission electron microscopy image (TEM) (Fig. 1b). The UVVis spectrum of the gold sol that prepared showed only one band with a maximum at $\lambda_{\max }=530 \mathrm{~nm}$. Moreover, the spectrum did not show a band at around $\lambda=680 \mathrm{~nm}$, which testifies to the absence of the aggregated gold particles (Fig. 1c) $[17,56,57]$.

The basic strategy and the proposed chemical mechanism for the preparation of modified electrodes used in the present paper (described above in Experimental) is illustrated in the scheme in Fig. 2. In the first stage of modification of the bare gold electrode, the attachment of dihydrolipoic acid to the gold electrode surface is realized via development of two covalent bonds between the $\mathrm{Au}$ and $\mathrm{S}$ atoms after $\mathrm{S}-\mathrm{H}$ bonds have been split in the dihydrolipoic acid molecule. It is generally accepted that chemisorption of alkanethiols and other Sfunctionalized aliphatic compounds on gold is preceded by the oxidative abstraction of hydrogen from S-H bonds [52, 58]. In the second step of modification, when the so-prepared electrode comes into contact with a solution of cysteamine, the $\mathrm{COOH}$ terminated group localized at the end of the dihydrolipoic acid layers attached to the gold surface atoms can be easily bonded to the amine group of cysteamine. By comparison of the $\mathrm{p} K_{\mathrm{a}}$ values of dihydrolipoic acid and cysteamine, it is known that the carboxylic groups of dihydrolipoic acid $\left(\mathrm{p} K_{\mathrm{a}}=4.90\right)$ (www.ChemAxon.com) are mostly dissociated at $\mathrm{pH}=7$ of the electrolyte solution and the $\mathrm{COO}^{-}$terminated negatively charged layers of the dihydrolipoic acid may favourably interact with the positively charged part (i.e. with the protonated $\mathrm{NH}_{3}{ }^{+}$group) of cysteamine $\left(\mathrm{p} K_{\mathrm{a}}=8.35\right.$ and $\left.\mathrm{p} K_{\mathrm{a}}=10.81\right)$ (www. Reaxys. com). Moreover, strong hydrogen bonds can be formed between carboxylic groups of dihydrolipoic acid and the $\mathrm{NH}_{2}$ group of cysteamine [45]. This explains development of a stable DHLA/CA complex exposed with the SH group of cysteamine towards the top-side of the monolayer formed. Due to the second step, further modification of the $\mathrm{Au} / \mathrm{DHLA} / \mathrm{CA}$ template with gold nanoparticles, via formation of the covalent bonds between $\mathrm{S}$ atoms of cysteamine and the gold nanoparticles, is possible (Fig. 2). In this way, the $\mathrm{Au} / \mathrm{DHLA} / \mathrm{CA} / \mathrm{Au}-\mathrm{NPs}$ electrode with gold nanoparticles attached on the top of the SAM layer was obtained.

Figure 3 compares the stable cyclic voltammograms of the bare polycrystalline gold electrode (marked as Au electrode) with that obtained after modification with dihydrolipoic acid, cysteamine and gold nanoparticles recorded (after the 5th scan) in the supporting electrolyte solution, $60 \mathrm{mM}$ phosphate buffer, $\mathrm{pH}$ 7. As follows from Fig. 3 in a wide range of potential, no faradic processes occur on the electrode surface; only a charging/discharging of the double layer takes place. It should be noticed that because of the used way of the gold template activation, we have not observed on the $j-E$ curves any signals which may be connected with the gold surface reconstruction process, as it has been described in [59]. Well-defined anodic peaks at $E=0.62 \mathrm{~V}$ vs SCE and $E=0.61 \mathrm{~V}$ vs SCE, respectively, and moreover, the cathodic contra-peaks at $E=0.58 \mathrm{~V}$ vs SCE and $E=0.57 \mathrm{~V}$ vs SCE visible in the $j-E$ curves, recorded in the supporting electrolyte solution on the $\mathrm{Au}$ and $\mathrm{Au} / \mathrm{Au}-\mathrm{NPs}$ electrodes are assigned to the gold oxide formation and to its reduction, respectively [60]. There is no doubt that the surface area of the electrode after the modification process should increase [61]. As a result of the gold electrode modification, the roughness factor was changed. Taking into account the estimated values of the roughness factors of the modified and unmodified gold electrodes, it was found that the real surface area of the modified gold electrode prepared in this work $(r f=2.9)$ was about 1.8 time greater than that of the 
a)

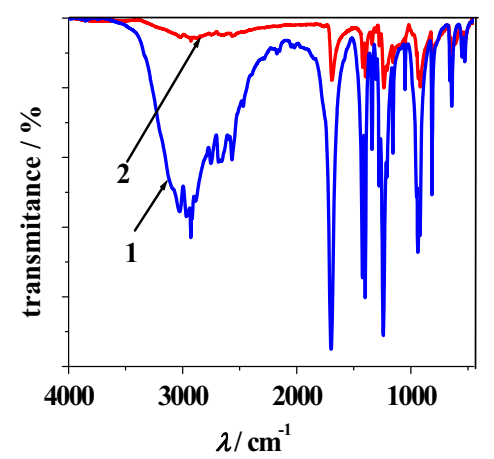

b)

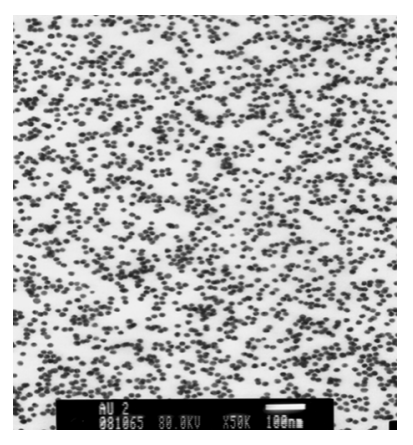

c)

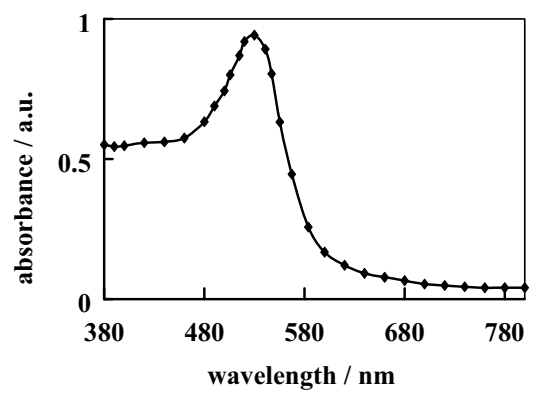

Fig. 1 a The transmission FT-IR spectra (1) and the reflectance spectra of dihydrolipoic acid adsorbed on the gold plate (2). b Transmission electron image of the gold nanoparticles. Scale bar: $100 \mathrm{~nm}$. c The optical UV-Vis spectrum of the colloidal gold solution

gold electrode $(r f=1.6)$. An indisputable increase in the roughness factor due to modification of gold template is well visible in the SEM images presented in Fig. 4. As previously reported, the sulphur-containing aliphatic carboxylic acids form well-organized monolayers on the bare gold electrode $[34,62]$. Most probably, such a structure ensures easier migration of reactants through the alkane chains to the electrode surface. This opinion is supported by the observation that the permeability of SAMs increases with higher levels of substrate roughness, [63] which was confirmed by using the infrared reflection-absorption spectroscopy method [64]. Nevertheless, the SAM layer effectively protects the metal surface against adsorption of reaction products poisonous for the electrode surface. Gold nanoparticles immobilized on the outer side of the SAM Au/DHLA/CA layer attached to the gold surface facilitate accumulation of the substance studied at the electrode-solution interface and efficiently promote tunnelling electrons between the alkane chains of the substance analysed and the electrode [65]. Thus, modification of the surface electrode not only increases the electrode surface area but also facilitates the charge transfer between the oxidized compound and the gold electrode.

\section{Oxidation of dopamine at bare and modified gold electrodes}

The electrochemical oxidation of dopamine in aqueous solution goes through three steps, according to the ECE mechanism well proven and widely adopted in literature (where $\mathrm{E}$ and $\mathrm{C}$ denote the electrochemical and the chemical steps, respectively) [66] presented below in Scheme 1. According to it, during the first electrochemical step, dopamine is oxidized to o-dopaminoquinone after exchange of two electrons and two protons. It is commonly known that the quinones are reactive and can be attacked by nucleophiles. Dopaminoquinine contains both an electron-deficient ring and an electron-donating amine group. When the amine group is unprotonated, the molecule can undergo a 1,4 Michael addition, which results in cyclization reactions [45]. Therefore, in the second step, the o-dopaminoquinone undergoes intramolecular cyclization via 1,4 Michael addition which leads to leucodopaminochrome. Leucodopaminochrome is easily oxidized in the third step to dopaminochrome. The latter product may be subsequently transformed into melanin polymers [27]. Figure 5 presents the cyclic voltammetric responses in the presence of $0.5 \mathrm{mM}$
Fig. 2 Scheme and the proposed chemical mechanism of the successive steps of modification of a bare gold electrode with: dihydrolipoic acid, cysteamine and the gold nanoparticles

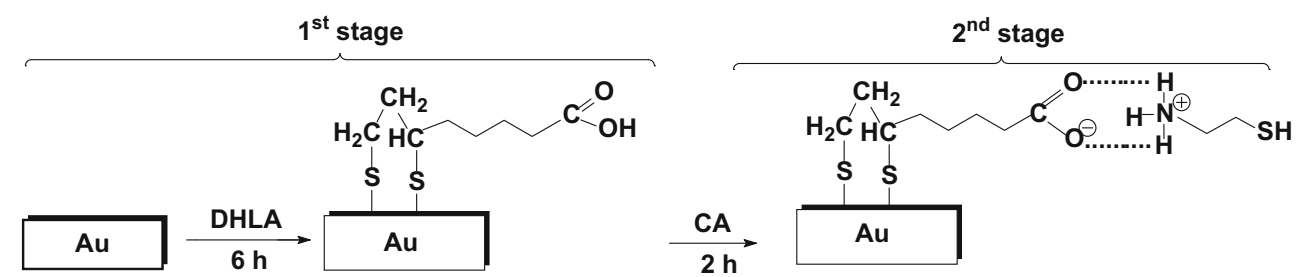

$3^{\text {rd }}$ stage

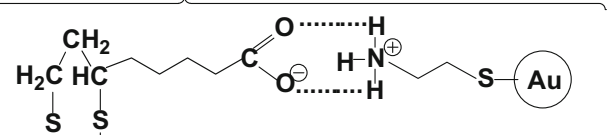




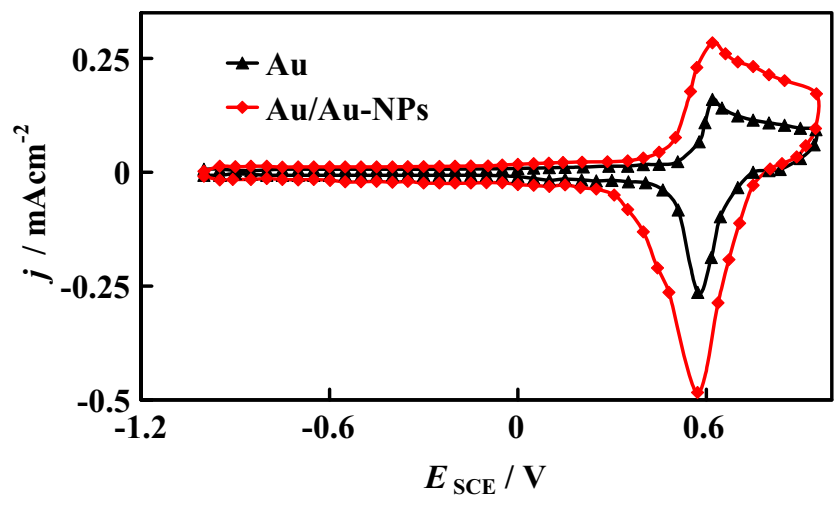

Fig. 3 Cyclic voltammograms of $\mathrm{Au}$ and $\mathrm{Au} / \mathrm{Au}-\mathrm{NPs}$ electrodes in $60 \mathrm{mM}$ phosphate buffer, $\mathrm{pH} 7 ; v=0.1 \mathrm{~V} \mathrm{~s}^{-1}$

of dopamine at the bare gold electrode (Au) (Fig. 5a) and at the modified gold electrode (Au/Au-NPs) (Fig. 5b), respectively. For comparison, in Fig. 5a, b, the CVs recorded at a given electrode in pure supporting electrolyte solution are included. Moreover, Fig. 5c compares cyclic voltammograms recorded for $0.5 \mathrm{mM}$ dopamine at the studied electrodes in the same experimental conditions. The evolution of the current densities after successive cycles may be useful to give information about the poisoning of the surface, but in this study, the current densities did not alter after successive scans, so the fouling effect of the electrode surfaces was not observed during dopamine electrooxidation. According to Fig. 5a, at the gold electrode, the anodic peak (IA) with the maximum at $E=0.25 \mathrm{~V}$ vs SCE and with the peak current density $j_{p}=0.22$ $\mathrm{mAcm}_{-2}$ as well as the cathodic peak (IC) with the maximum at $E=0.18 \mathrm{~V}$ vs SCE and with the peak current density $j_{p-}$ $=-0.19 \mathrm{mAcm}_{-2}$ is assigned to the reversible dopamine oxidation to dopaminoquinone. As it was said above, the dopaminoquinone molecule undergoes the 1,4-Michael addition which leads to leucodopaminochrome. In the next electrochemical step, leucodopaminochrome is reversibly oxidized to dopaminochrome. The latter process is visible on $\mathrm{CV}$ as a reversible couple of peaks. The anodic peak at $E=-0.30 \mathrm{~V}$ vs SCE with the peak current density a)

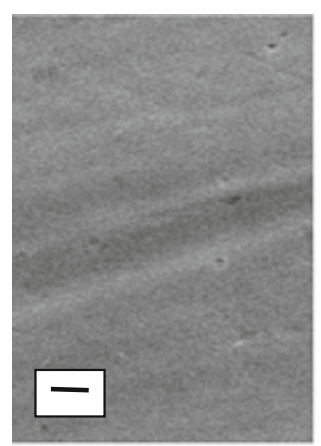

\section{b)}

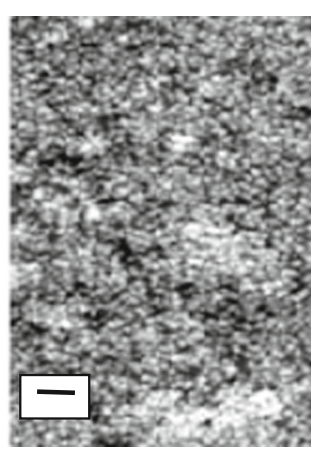

Fig. 4 Scanning electron micrographs of $\mathbf{a}$ the bare Au surface and $\mathbf{b}$ the modified $\mathrm{Au} / \mathrm{Au}-\mathrm{NPs}$ surface; scale bar $2 \mu \mathrm{m}$. Magnification 10,000; accelerating voltage $10 \mathrm{kV}$<smiles>NCCc1ccc(O)c(O)c1</smiles><smiles>CC(C)(C)[PbH2]</smiles><smiles>NCCC1=CC(=O)C(=O)C=C1</smiles><smiles>NCCC1=CC(=O)C(=O)C=C1</smiles>

(C)<smiles>Oc1cc2c(cc1O)NCC2</smiles><smiles>Oc1cc2c(cc1O)NCC2</smiles>
$\frac{-2 \mathrm{e},-2 \mathrm{H}^{+}}{(\mathrm{E})}$<smiles>O=C1C=C2CCNC2=CC1=O</smiles>

Scheme 1 Electrochemical oxidation of dopamine [66]

a)

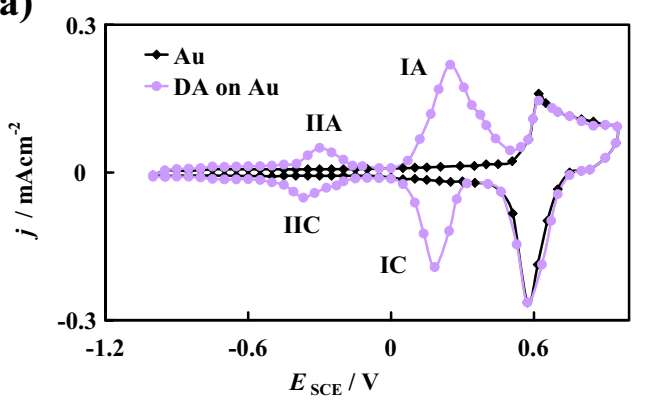

b)

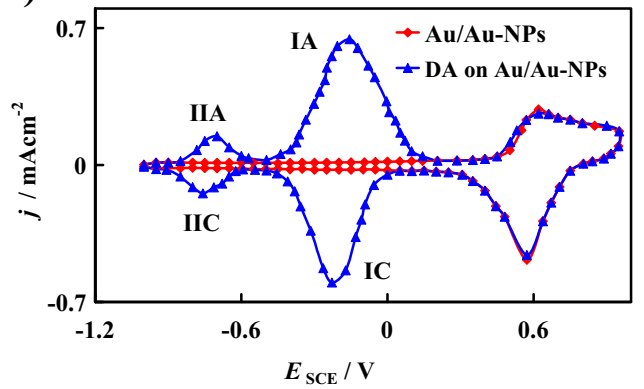

c)

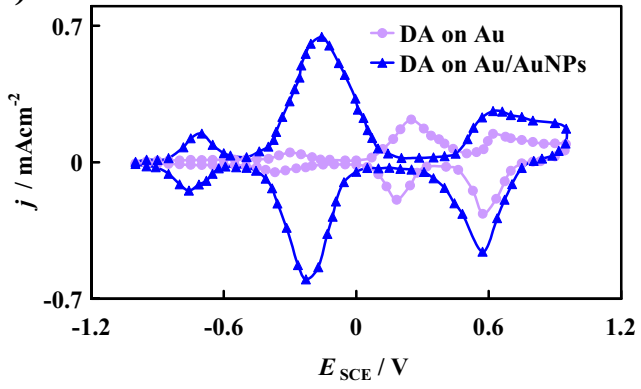

Fig. 5 CVs in $60 \mathrm{mM}$ phosphate buffer, $\mathrm{pH} 7$, with $0.5 \mathrm{mM}$ dopamine at a $\mathrm{Au}, \mathbf{b} \mathrm{Au} / \mathrm{Au}-\mathrm{NPs}$ electrodes and $\mathbf{c}$ comparison of $\mathrm{CVs}$ recorded for $0.5 \mathrm{mM}$ dopamine at the $\mathrm{Au}$ and $\mathrm{Au} / \mathrm{Au}-\mathrm{NPs}$ electrodes; $v=0.1 \mathrm{~V} \mathrm{~s}^{-1}$. The meaning of the assigned peaks: IA the peak responsible for electrooxidation of dopamine to dopaminoquinone, IC the peak responsible for electroreduction of dopaminoquinone to dopamine, IIA the peak responsible for electrooxidation of leucodopaminochrome to dopaminochrome, IIC the peak responsible for electroreduction of dopaminochrome to leucodopaminochrome 
$j_{p}=0.05 \mathrm{~mA} \mathrm{~cm}{ }^{-2}$ is responsible for leucodopaminechrome oxidation to dopaminochrome (IIA) while the cathodic peak (IIC) at $E=-0.37 \mathrm{~V}$ vs SCE with the peak current density $j_{p}=-0.053 \mathrm{~mA} \mathrm{~cm}^{-2}$ is assigned to dopaminochrome reduction to leucodopaminechrome.

Meanwhile, in the same experimental conditions, for of dopamine oxidation at the modified gold electrode (Fig. 5b), the anodic peak (IA) reaches the maximum current density at $E=-0.16 \mathrm{~V}$ vs SCE with $j_{p}=0.64 \mathrm{~mA} \mathrm{~cm}^{-2}$ while the (IC) peak appears at $E=-0.23 \mathrm{~V}$ vs SCE and the current density obtained in this peak reaches $j_{p}=-0.60 \mathrm{~mA} \mathrm{~cm}^{-2}$. The second couple of peaks responsible for reversible leucodopaminechrome oxidation is visible, at $E=-0.70 \mathrm{~V}$ vs SCE with $j_{p}=0.145 \mathrm{~mA} \mathrm{~cm}{ }^{-2}$ in the anodic scan (peak IIA) and at $E=-0.76 \mathrm{~V}$ vs SCE with $j_{p}=-0.15 \mathrm{~m} \mathrm{Acm}^{-2}$ in the cathodic scan (peak IIC). In the following, analysis of experimental data will be made only for peak (IA) assigned to the reversible dopamine oxidation to dopaminoquinone.

According to the electrochemical kinetics theory, in the evaluation of the catalytic effect, two factors should be considered: (i) an increase in the current density and (ii) a decrease in the overpotential of oxidation. These facts lead to improvement in the electrocatalytic effect on the kinetics of the electrode reactions [61]. The results presented in Fig. 5 prove that the electrode material used in this work contributes to achieving a high catalytic effect during dopamine oxidation. This is manifested as a substantial shift of the corresponding voltammetric peaks towards the negative potential direction accompanied by an increase in the current response at the peaks maximum in comparison with that characteristic of the bare gold electrode. By taking into consideration the quotient of $j_{\mathrm{p}}$ values and roughness factor, in order to eliminate the effect of increase in the real area of the electrode surface as a result of its coverage with dihydrolipoic acid, cysteamine and the gold nanoparticles, it was found that the rate of electron transfer during the dopamine oxidation at the potential of peak maximum on the $\mathrm{Au} / \mathrm{Au}-\mathrm{NPs}$ electrode is faster, relative to that on the unmodified Au electrode. Taking into consideration the quotient of $j_{\mathrm{p}}$ value of IA and the roughness factor of the modified and unmodified electrodes $(2.9 / 1.6=1.6)$, it was expected that the current density for dopamine electrooxidation on the $\mathrm{Au} / \mathrm{Au}-\mathrm{NPs}$ electrode should be equal to about $0.4 \mathrm{~mA} \mathrm{~cm}{ }^{-2}$ while it reached $0.64 \mathrm{~mA} \mathrm{~cm}^{-2}$. Meanwhile, it was found that the rate of electron transfer during the dopamine oxidation at the potential of peak maximum on the $\mathrm{Au} / \mathrm{Au}-\mathrm{NPs}$ electrode was about 2.9-fold faster, relative to that on the unmodified Au electrode. It means that besides the effect of increase in the real area of the electrode surface as a result of its coverage with dihydrolipoic acid, cysteamine and the gold nanoparticles during the modification process, another effect must also be responsible for such a high $j_{\mathrm{p}}$ value reached at the $\mathrm{Au} / \mathrm{Au}-\mathrm{NPs}$ electrode. It is worth emphasizing that such high $j_{p}$ values corresponding to the dopamine oxidation may indicate the presence of specific interactions of dopamine molecules with the electrode modified with SAM layer prepared with the gold template, dihydrolipoic acid, cysteamine and the gold nanoparticles. Such interactions result in a decrease in the energy barrier for the oxidative electron transfer $[61,67]$.

Effect of solution $\mathrm{pH}$ and the potential scan rate on the current response of dopamine electrooxidation

For both gold electrodes under investigation, it was found that the potential of anodic current peaks attributed to the reversible oxidation of dopamine to dopaminoquinone was shifted towards higher (i.e. more positive values) electrode potentials with decreasing $\mathrm{pH}$ of the investigated solution. Furthermore, analysis of the CVs revealed almost the same influence of the solution $\mathrm{pH}$ on the current peak density $\left(j_{\mathrm{p}}\right)$ on both type of electrodes investigated, albeit the rate of dopamine oxidation was found to be strongly influenced by the electrode composition. Maximum current densities were obtained in the $\mathrm{pH}$ range between 6 and 8 (see Fig. 6a). Hence, taking into account the prospective practical application of the bare and modified gold electrodes as sensors in physiological systems, all our experiments were carried out in a buffer solution of $\mathrm{pH}=7$.

Scan rate is one of the parameters significantly affecting the electrooxidation of various compounds. For both the $\mathrm{Au}$ and $\mathrm{Au} / \mathrm{Au}-\mathrm{NPs}$ electrodes, it was observed that the oxidation peak potentials shift positively with increasing potential sweep rate. A linear relationship between the current peak density $\left(j_{\mathrm{p}}\right)$ corresponding to the dopamine oxidation and the square root of the scan rate $\left(v^{1 / 2}\right)$ was obtained for both electrodes investigated for the scan rate in the range from $v=0.001$ to $v=0.2 \mathrm{~V} \mathrm{~s}^{-1}$ (Fig. 6b). Analysis of the experimental data by using the linear regression revealed an average slope of $\mathrm{d} \log \left(j_{\mathrm{p}} / \mathrm{mA} \mathrm{cm}^{-2}\right) / \mathrm{d} \log \left(v / \mathrm{V} \mathrm{s}^{-1}\right)=0.51 \pm 0.02$ $\left(R^{2} \geq 0.997 ; n=15\right)$ (Fig. 6c). From the kinetic point of view, for a purely diffusion-controlled process, the value of the $\mathrm{d} \log$ $\left(j_{\mathrm{p}} / \mathrm{mA} \mathrm{cm}^{-2}\right) / \mathrm{d} \log \left(v / \mathrm{V} \mathrm{s}^{-1}\right)$ slope should be 0.5 , while for a purely adsorption-controlled process, it should be 1 [61]. Accordingly, the overall rate of dopamine oxidation at the potential of peak maximum under the abovementioned experimental conditions is limited by diffusion being slower than both adsorption of dopamine and the following charge transfer at the electrode/solution interface. This relation is favourable for quantitative determination of the dopamine concentration in the electrolyte solution [61].

\section{Quantitative analysis of dopamine electrooxidation}

As mentioned above, in evaluation of the catalytic effect of different electrodes on the electrooxidation process, a decrease in the overpotential of oxidation and an increase in the current 
a)

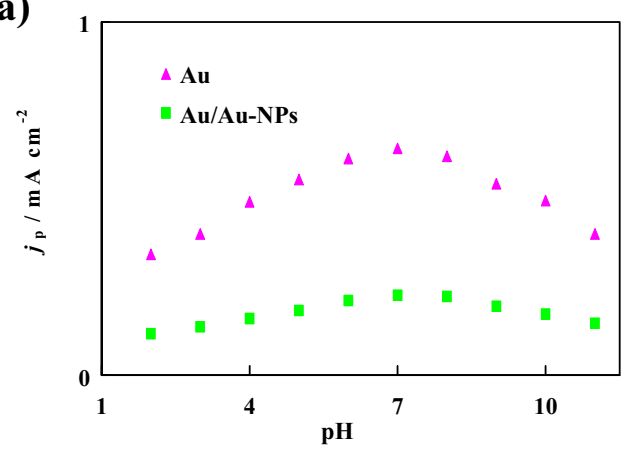

b)

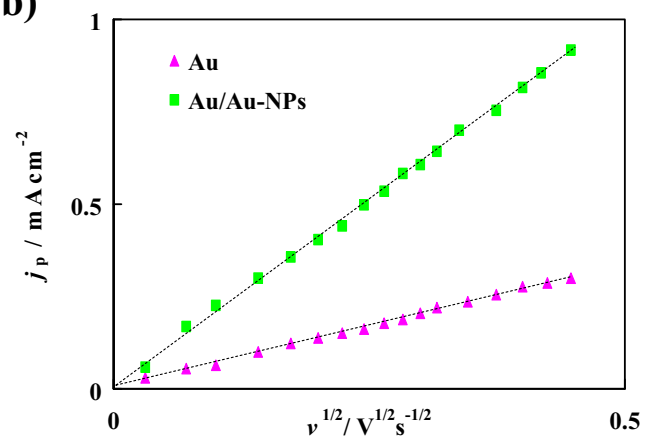

c)

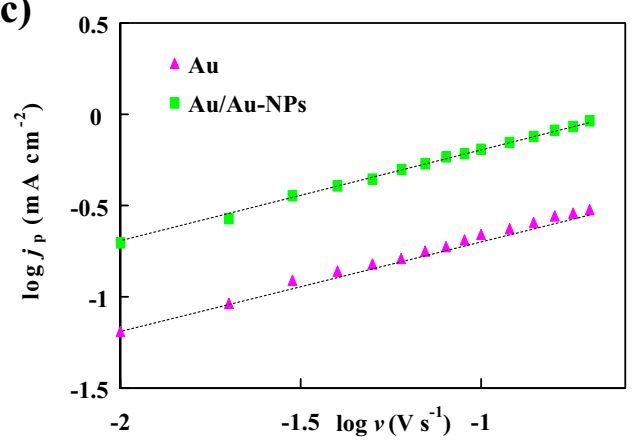

Fig. 6 Effect of $\mathrm{pH}$ on a the current peak density of the oxidation of $0.5 \mathrm{mM}$ dopamine at the $\mathrm{Au}$ and $\mathrm{Au} / \mathrm{Au}-\mathrm{NPs}$ electrodes; $v=0.1 \mathrm{~V} \mathrm{~s}^{-1} . \mathbf{b}$ Dependence of the current peak density on the square root of potential scan rate. $\mathbf{c}$ Dependence of the current peak density on the potential scan rate in double logarithm coordinates for the oxidation of $0.5 \mathrm{mM}$ dopamine at the $\mathrm{Au}$ and $\mathrm{Au} / \mathrm{Au}-\mathrm{NPs}$ electrodes

density should be considered. Without doubt, the modified electrode prepared in this work simultaneously satisfies both these conditions, so that it appears to be beneficial for analytical application. Since dopamine plays an important role in medicine, its accurate quantitative determination is very important. However, as mentioned in the introduction and as shown in Fig. 7a, precise detection of dopamine on the bare gold electrode is practically impossible in samples containing interfering biogenic compounds, like ascorbic acid and uric acid, as the cyclic voltammetric responses of these compounds overlap. This problem is removed when the modified gold electrode developed in this work is applied in the analysis of the ternary mixture containing dopamine, ascorbic acid and
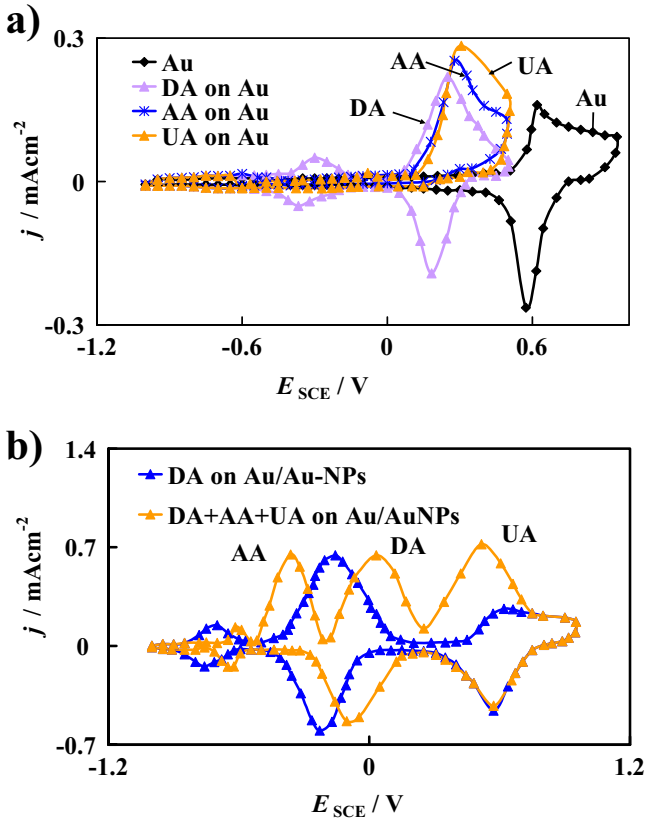

Fig. $7 \mathrm{CVs}$ of the $\mathrm{Au}$ (a) and b $\mathrm{Au} / \mathrm{Au}-\mathrm{NPs}$ electrodes in $60 \mathrm{mM}$ phosphate buffer, $\mathrm{pH}=7$, with $0.5 \mathrm{mM}$ dopamine $+1 \mathrm{mM}$ of ascorbic acid $+1 \mathrm{mM}$ of uric acid; $v=0.1 \mathrm{~V} \mathrm{~s}^{-1}$

uric acid. It is evident from the CVs in Fig. $7 \mathrm{~b}$ that the current peaks corresponding to the oxidation of the mentioned compounds coexisting in a buffer solution of $\mathrm{pH} 7$ are clearly separated from each other. When using the prepared, in this work, gold electrode modified with SAM layers composed with dihydrolipoic acid, cysteamine and the gold nanoparticles, the peak potential separations between dopamine and ascorbic acid $\left(\Delta E_{\mathrm{DA}-\mathrm{AA}}=0.39 \mathrm{~V}\right)$, between dopamine and uric acid $\left(\Delta E_{\mathrm{DA}-\mathrm{UA}}=0.50 \mathrm{~V}\right)$ and between ascorbic acid and uric acid $\left(\Delta E_{\mathrm{AA}-\mathrm{UA}}=0.89 \mathrm{~V}\right)$ are much greater at the prepared modified gold electrode in comparison with those at the unmodified gold electrode $\left(\Delta E_{\mathrm{DA}-\mathrm{AA}}=0.03 \mathrm{~V}\right),\left(\Delta E_{\mathrm{DA}-}\right.$ $\mathrm{UA}=0.06 \mathrm{~V})$ and $\left(\Delta E_{\mathrm{AA}-\mathrm{UA}}=0.028 \mathrm{~V}\right)$. Since the gold nanoparticles used in the present paper are stabilized by citrate and thus target the negative charge $[68,69]$, it seems reasonable to conclude that their chemisorption on the top of the prepared SAM layers leads to a SAM matrix with an excess of negative charge. Thus, the electrode surface covered by the prepared SAM film should repel anionic species through electrostatic repulsion while cationic species should be attracted. Taking into account the values of $\mathrm{p} K_{a}=8.87, \mathrm{p} K_{a}=4.1$ and $\mathrm{p} K_{a}=5.4$ for dopamine, ascorbic acid and uric acid, respectively [35], the respective potential shift of the DA, AA and UA peak currents may be attributed to the electrostatic attraction and repulsion of DA and both AA and UA, respectively, and the negatively charged SAM-modified layer. Taking the above into account, the peak-to-peak separations obtained on modified electrode confirm that the newly prepared modified gold electrode appears to be a good candidate for selective detection and analytical determination of DA in the presence of AA 
and UA and determination of AA and UA in the presence of DA.

Information on the detection sensitivity of the new modified electrodes towards simultaneous and/or individual determination of dopamine, ascorbic acid and uric acid resulted from experiments performed with the differential pulse voltammetry by changing the concentration of one compound with the other two kept constant. Figure $8 \mathrm{a}(a-c)$ exemplifies the respective DPV responses of the $\mathrm{Au} / \mathrm{Au}-\mathrm{NPs}$ electrode. The studied dopamine concentration range was from 0.0001 to $5 \mathrm{mM}$, while concentrations of ascorbic acid and uric acid were varied from 0.5 to $5 \mathrm{mM}$. There is no doubt that the modified electrode is suitable for precise determination of dopamine concentration without any interference of ascorbic acid and uric acid.

Analysis of DPVs for the prepared electrode revealed that the current peak density $\left(j_{\mathrm{p}}\right)$ corresponding to electrooxidation of dopamine to dopaminoquinone was proportional to its concentration $\left(c_{\mathrm{DA}}\right)$ over the range of 0.0001 to $0.5 \mathrm{mM}$ and to $0.85 \mathrm{mM}$ at the gold and the modified gold electrode, respectively (see Fig. $8 \mathrm{~b}(d)$ ). It is worth noting that at the same time, the proportional increase in $j_{\mathrm{p}}$ with the analyte concentration was observed for the current peak assigned both to ascorbic acid and uric acid oxidation in the whole concentration range

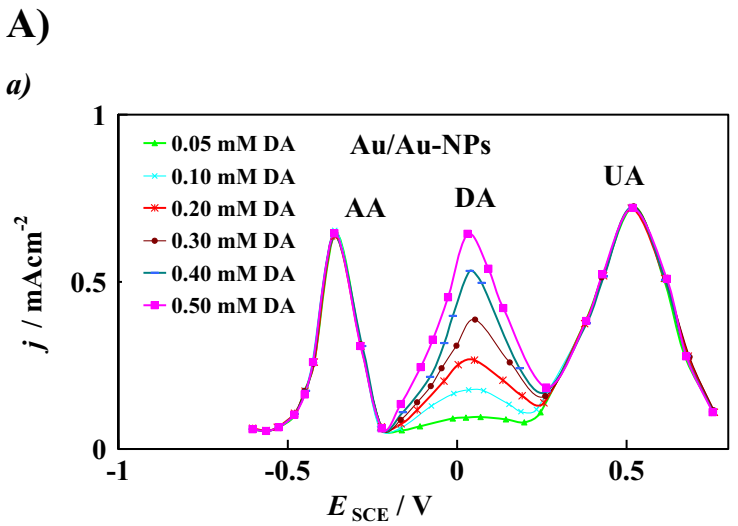

B)

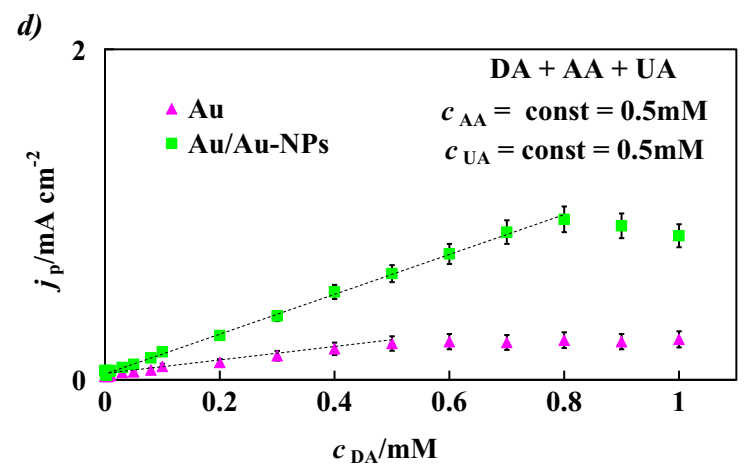

b)

e)
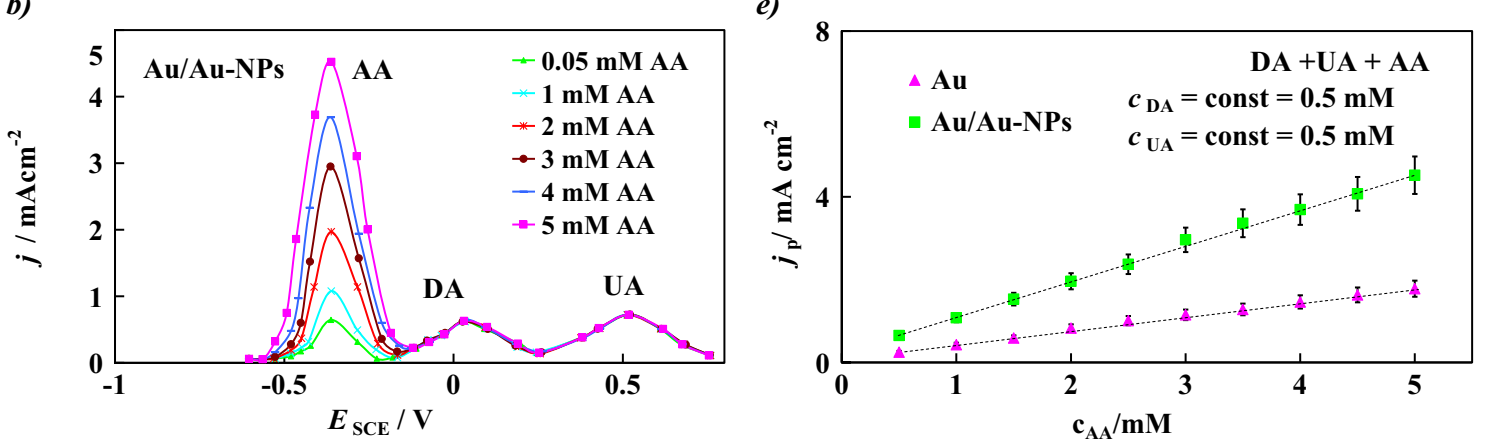

c)

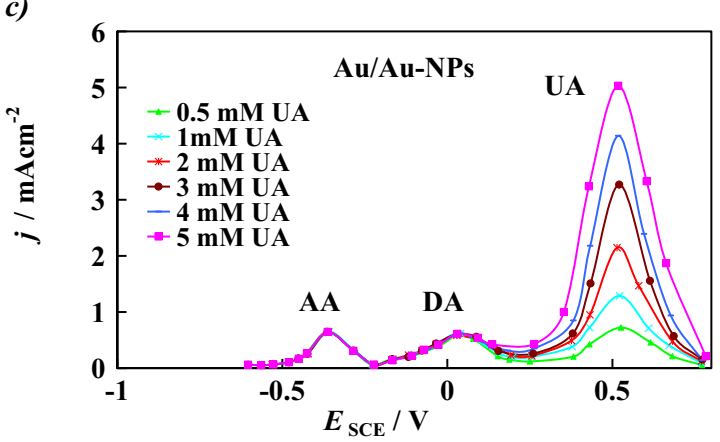

f)

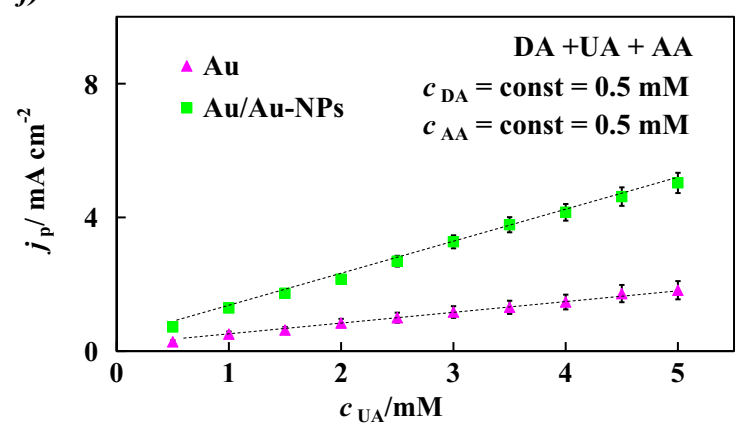

Fig. 8 a $a$ DPVs at the Au/Au-NPs electrode in $60 \mathrm{mM}$ phosphate buffer, $\mathrm{pH} 7$, with $0.5 \mathrm{mM}$ ascorbic acid $+0.5 \mathrm{mM}$ uric acid and different concentrations of dopamine; $b$ with $0.5 \mathrm{mM}$ dopamine $+0.5 \mathrm{mM}$ uric acid and different concentrations of ascorbic acid; $c$ and with $0.5 \mathrm{mM}$ dopamine $+0.5 \mathrm{mM}$ ascorbic acid and different concentrations of uric

acid; $v=0.1 \mathrm{~V} \mathrm{~s}^{-1}$; amplitude $50 \mathrm{mV}$; pulse width $100 \mathrm{~ms}$; pulse period $200 \mathrm{~ms}$. b Current peak density versus $d$ dopamine, $e$ ascorbic acid and $f$ uric acid concentration in $60 \mathrm{mM}$ phosphate buffer, $\mathrm{pH} 7$, for the $\mathrm{Au}$ and $\mathrm{Au} / \mathrm{Au}-\mathrm{NPs}$ electrodes; $v=0.1 \mathrm{~V} \mathrm{~s}^{-1}$ 
Table 1 Linear regression parameters and detection limits for determination of dopamine and ascorbic and uric acids on $\mathrm{Au}$ and $\mathrm{Au} / \mathrm{Au}-\mathrm{NPs}$ electrodes; $v=0.1 \mathrm{~V} \mathrm{~s}^{-1}$

\begin{tabular}{|c|c|c|c|c|}
\hline Electrode & Compound & Regression equation & $\mathrm{R}^{2}(n)$ & $\begin{array}{l}\text { Detection limit } c_{L} / \\
\mathrm{mM}\left(\mathrm{c}_{\mathrm{L}} / \mu \mathrm{M}\right)\end{array}$ \\
\hline \multirow[t]{3}{*}{$\mathrm{Au}$} & DA & $\begin{array}{l}j_{\mathrm{p}}\left[\mathrm{mAcm}^{-2}\right]=(25 \pm 2) 10^{-3}+(402 \pm 6) \\
\quad 10^{-3} c_{\mathrm{DA}}[\mathrm{mM}]\end{array}$ & $\begin{array}{l}0.9925(15) \\
\quad(n=16)\end{array}$ & $5.1 \times 10^{-4}(0.51 \mu \mathrm{M})$ \\
\hline & $\mathrm{AA}$ & $\begin{array}{c}j_{\mathrm{p}}\left[\mathrm{mAcm}^{-2}\right]=(107 \pm 5) 10^{-3}+ \\
(340 \pm 8) 10^{-3} c_{\mathrm{AA}}[\mathrm{mM}]\end{array}$ & $\begin{array}{l}0.9967(10) \\
\quad(n=10)\end{array}$ & $13 \times 10^{-3}(13 \mu \mathrm{M})$ \\
\hline & UA & $\begin{array}{c}j_{\mathrm{p}}\left[\mathrm{mAcm}^{-2}\right]=(138 \pm 7) 10^{-3}+ \\
(340 \pm 5) 10^{-3} c_{\mathrm{UA}}[\mathrm{mM}]\end{array}$ & $\begin{array}{r}0,997110) \\
(\mathrm{n}=10)\end{array}$ & $14 \times 10^{-3}(14 \mu \mathrm{M})$ \\
\hline \multirow[t]{3}{*}{$\begin{array}{l}\mathrm{Au} / \mathrm{Au}- \\
\mathrm{NPs}\end{array}$} & $\mathrm{DA}$ & $\begin{array}{l}j_{\mathrm{p}}\left[\mathrm{mAcm}^{-2}\right]=(42 \pm 1) 10^{-3}+(20 \pm 3) \\
\quad 10^{-3} c_{\mathrm{DA}}[\mathrm{mM}]\end{array}$ & $\begin{array}{l}0.9986(18) \\
\quad(n=18)\end{array}$ & $\begin{array}{l}2.3 \times 10^{-5} \\
\quad(0,023 \mu \mathrm{M})\end{array}$ \\
\hline & $\mathrm{AA}$ & $\begin{array}{c}j_{\mathrm{p}}\left[\mathrm{mAcm}^{-2}\right]=(240 \pm 6) 10^{-3}+ \\
(865 \pm 4) 10^{-3} c_{\mathrm{AA}}[\mathrm{mM}]\end{array}$ & $\begin{array}{l}0.9979(10) \\
\quad(\mathrm{n}=10)\end{array}$ & $10 \times 10^{-3}(10 \mu \mathrm{M})$ \\
\hline & UA & $\begin{array}{c}j_{\mathrm{p}}\left[\mathrm{mAcm}^{-2}\right]=(288 \pm 6) 10^{-3}+ \\
(970 \pm 9) 10^{-3} c_{\mathrm{UA}}[\mathrm{mM}]\end{array}$ & $\begin{array}{l}0.9981(10) \\
\quad(\mathrm{n}=10)\end{array}$ & $12 \times 10^{-3}(12 \mu \mathrm{M})$ \\
\hline
\end{tabular}

applied (Fig. $8 \mathrm{~b}(e, f))$. The respective linear regression equations obtained for each electrode studied with the correlation coefficient $R^{2}$ near 1 are given in Table 1 . Moreover, the detection limits $\left(c_{\mathrm{L}}\right)$ for the compounds investigated were estimated according to the formula recommended by IUPAC: $c_{\mathrm{L}}=3 s_{\mathrm{b}} / S$ [70], where $s_{\mathrm{b}}$ is the standard deviation of the current density of the supporting electrolyte solution and $S$ is the slope of the linear $j_{\mathrm{p}}-c_{\mathrm{DA}}, j_{\mathrm{p}}-c_{\mathrm{AA}}$ or $j_{\mathrm{p}}-c_{\mathrm{UA}}$ dependences. It should be emphasized that the lower the detection limit, the lower the analyte concentration that can be detected. For a comparison of the dopamine $c_{\mathrm{L}}$ obtained on the prepared, in this work, electrode with the other ones obtained on different Au-modified electrodes, see [35, 37].

From the data presented in Table 1, it is evident that the detection limit of dopamine is lower for the modified electrode, in comparison with that found for the unmodified gold electrode. Most probably, the gold nanoparticles, covalently immobilized on the top side of the self-assembled Au/DHLA/ CA layer, promote accumulation of dopamine at the electrode/ solution interface and act as an "electron antennae," efficiently tunnelling electrons between the solute and the electrode and this contributes to the increase in the electrode sensitivity
Table 2 Comparison of detection limits for determination of dopamine obtained in this work and in literature

\begin{tabular}{lllc}
\hline $\begin{array}{l}\text { Template of the } \\
\text { sensor }\end{array}$ & Modifying agents & $\begin{array}{l}\text { Detection } \\
\text { limit }\end{array}$ & Ref. \\
\hline Gold & & $0.51 \mu \mathrm{M}$ & $\begin{array}{c}\text { This } \\
\text { work }\end{array}$ \\
Gold & Gold nanoparticles, cysteamine, ( \pm )dihydrolipoic acid & $0.023 \mu \mathrm{M}$ & $\begin{array}{c}\text { This } \\
\text { work }\end{array}$ \\
Graphite & Graphene & $10 \mu \mathrm{M}$ & {$[15]$} \\
Glassy carbon & Multiwalled carbon nanotubes with methylene blue & $0.23 \mu \mathrm{M}$ & {$[21]$} \\
Glassy carbon & Poly(caffeic acid) & $0.04 \mu \mathrm{M}$ & {$[22]$} \\
Glassy carbon & Poly(2-a,ino-5-(4-pyridihyl)-1,2,3,3-thiadiazole & $0.20 \mu \mathrm{M}$ & {$[23]$} \\
Glassy carbon & Poly(orthanilic acid) multiwalled carbon nanotubes & $0.21 \mu \mathrm{M}$ & {$[24]$} \\
Glassy carbon & Nafion-ruthenium oxide & $5 \mu \mathrm{M}$ & {$[26]$} \\
Glassy carbon & Choline, glutamic acid & $1 \mu \mathrm{M}$ & {$[29]$} \\
Glassy carbon & Glycine, glutamic acid & $0.7 \mu \mathrm{M}$ & {$[29]$} \\
Silicon & Carbon nanotubes & $0.3 \mu \mathrm{M}$ & {$[16]$} \\
Gold & Overoxidized dopamine film & $0.2 \mu \mathrm{M}$ & {$[27]$} \\
Gold & Overoxidized polyaniline film & $0.1 \mu \mathrm{M}$ & {$[28]$} \\
Gold & Quercetin & $1 \mu \mathrm{M}$ & {$[30]$} \\
Gold & Gold nanoparticles & $0.098 \mu \mathrm{M}$ & {$[35]$} \\
Gold & Mercaptopropionic acid, cysteamine, gold nanoparticles & $0.040 \mu \mathrm{M}$ & {$[35]$} \\
Gold & Thiodipropionic acid, cysteamine, gold nanoparticles & $0.062 \mu \mathrm{M}$ & {$[35]$} \\
Gold & Dithiodipropionic acid, cysteamine, gold nanoparticles & $0.022 \mu \mathrm{M}$ & {$[35]$} \\
Gold & 2,3-dimercaptosucconic acid, cysteamine, gold & $0.044 \mu \mathrm{M}$ & {$[37]$} \\
& $\quad$ nanoparticles & & \\
\hline & & &
\end{tabular}


Table 3 Determination results of dopamine and ascorbic and uric acids in the prepared samples

\begin{tabular}{lllllll}
\hline $\begin{array}{l}\text { No. of } \\
\text { sample }\end{array}$ & $\begin{array}{l}\text { DA } \\
\text { content } \\
(\mathrm{mM})\end{array}$ & $\begin{array}{l}\text { AA } \\
\text { content } \\
(\mathrm{mM})\end{array}$ & $\begin{array}{l}\text { UA } \\
\text { content } \\
(\mathrm{mM})\end{array}$ & $\begin{array}{l}\text { DA } \\
\text { concentration } \\
\text { fund (mM) }\end{array}$ & $\begin{array}{l}\text { AA } \\
\text { concentration } \\
\text { fund (mM) }\end{array}$ & $\begin{array}{l}\text { UA } \\
\text { concentration } \\
\text { fund (mM) }\end{array}$ \\
\hline 1 & 0.013 & 5 & 5 & 0.0134 & 5.02 & 5.03 \\
2 & 0.013 & 5 & 5 & 0.0128 & 4.96 & 4.98 \\
3 & 0.013 & 5 & 5 & 0.0132 & 4.93 & 5.12 \\
4 & 0.013 & 5 & 5 & 0.0129 & 5.11 & 4.95 \\
5 & 0.013 & 5 & 5 & 0.0135 & 5.04 & 5.08 \\
$\begin{array}{c}\text { R.S.D. } \\
(\%)\end{array}$ & & & & $4.17 \%$ & $3.2 \%$ & $3.7 \%$ \\
$\begin{array}{c}\text { Recovery } \\
(\%)\end{array}$ & & & & $98-103 \%$ & $98-104 \%$ & $96-102 \%$ \\
\hline
\end{tabular}

towards dopamine detection [65]. Having analysed the results of our study reported in the present paper and in our previous projects as well as other results reported in literature and related to the modification of gold electrodes for dopamine sensing, we have concluded that the dopamine detection level depends to a high extent on the molecular structure that linked the surface of gold with gold nanoparticles (the lower detection limit means the possibility of detection of lower concentrations of the analyte). It is worth noting that the dopamine detection limit achieved in the present study is in the most cases lower than the detection limits reached for the other modified electrodes presented in literature and listed in Table 2 .

\section{Sample analysis}

The prepared samples were examined electrochemically and then the concentrations of dopamine, ascorbic acid and uric acid were estimated using the calibration method. All the measurements were repeated three times under the same experimental conditions. The results of the determination are listed in Table 3. The relative standard deviations (R.S.D. (\%)) and the recovery ranges of determination of each compound in the prepared samples are included in Table 3. The statistical parameters show a good agreement with the standard content and indicate that the new prepared voltammetric sensor could be promising for the simultaneous determination of dopamine, ascorbic acid and uric acid in ternary mixtures.

\section{Conclusions}

It was demonstrated that the rate of dopamine oxidation, a compound of great biological importance, was substantially enhanced on gold surfaces modified with self-assembled layers composed with $( \pm$ ) dihydrolipoic acid, cysteamine and gold nanoparticles ( $\mathrm{Au} / \mathrm{Au}-\mathrm{Au}-\mathrm{NPs}$ ) when compared to that achieved at a bare gold electrode $(\mathrm{Au})$. The voltammetric sensors prepared exhibited excellent stability and reproducibility. The preparation procedure of the modified electrode is simple and green without using toxic solutions, which is important from not only the medical but also the ecological point of view. The range of dopamine concentration in which its content can be reliably estimated as well as the dopamine detection limit obtained on modified electrode is sufficient for practical use, and thus, the obtained modified gold electrode is much promising for application as a sensitive voltammetric dopamine sensor. Analysing our previous projects related to the modification of gold electrodes for dopamine sensing, we have concluded that large significance for the dopamine detection level has a molecular structure that linked the surface of gold with gold nanoparticles. At this point, it should be considered whether the changing of the size of the gold nanoparticles would affect the detection level. It will be the focus of our future research.

Acknowledgments The Ministry of Scientific Research, Poland, is gratefully acknowledged for the financial support of this work.

Open Access This article is distributed under the terms of the Creative Commons Attribution 4.0 International License (http:// creativecommons.org/licenses/by/4.0/), which permits unrestricted use, distribution, and reproduction in any medium, provided you give appropriate credit to the original author(s) and the source, provide a link to the Creative Commons license, and indicate if changes were made.

\section{References}

1. Stryer L (1999) Biochemistry. PWN, Warsaw

2. Patric GL (2005) An introduction to medical chemistry. Oxford University Press Inc, New York

3. Smith TE (2005) In: Devlin TM (ed) Textbook of biochemistry with clinical correlations. Willey-Liss, New York

4. Cooper JR, Bloom FE, Roth RH (1982) The biochemical basis of neuropharmacology. Oxford University Press, Oxford

5. Ferreira FDP, Silva LIB, Freitas AC, Rocha-Santosa TAP, Duarte AC (2009) J Chromatogr A 1216:7049-7054 
6. Sakaguchi Y, Yoshida H, Hayama T, Itoyama M, Todoroki K, Yamaguchi M, Notha H (2011) J Chromatogr A 1218:5581-5586

7. Ferry B, Gifu EP, Sandu I, Denoroy L, Parrot S (2014) J Chromatogr B 951:52-57

8. Lua H, Yu J, Wang J, Wu L, Xiao H, Gao R (2016) J Pharm Biomed Anal 122:42-45

9. Moghadam MR, Dadfarnia S, Shabani AMH, Shahbazikhah P (2011) Anal Biochem 410:289-295

10. Kong B, Zhu A, Luo Y, Tian Y, Yu Y, Shi G (2011) Angew Chem 123:1877-1880

11. Gao Z, Huang H (1998) Chem Commun 106:2107-2108

12. Zhang L (2008) Microchim Acta 161:191-201

13. Sun Y, Fei J, Hou J, Zhang Q, Liu Y, Hu B (2009) Microchim Acta 165:373-379

14. Zhang L, Jiang X (2005) J Electroanal Chem 583:292-299

15. Mallesha M, Manjunatha R, Suresh GS, Melo JS, D'Souza SF, Venkatesha TV (2012) J Solid State Electrochem 16:2675-2681

16. Tsierkezos NG, Ritter U (2012) J Solid State Electrochem 16:22172226

17. Retna Raj C, Okajima T, Ohsaka T (2003) J Electroanal Chem 543: $127-133$

18. Wang P, Li Y, Huang X, Wang L (2007) Talanta 73:431-437

19. Hu GZ, Zhang DP, Wu WL, Yang ZS (2008) Coll Surf B 62:199 205

20. Jiang JJ, Du XZ (2014) Nanoscale 6:11303-11309

21. Yang S, Li G, Yang R, Xia M, Qu L (2011) J Solid State Electrochem 15:1909-1918

22. Li NB, Ren W, Luo HQ (2008) J Solid State Electrochem 12:693699

23. Zhang L, Wang L (2013) J Solid State Electrochem 17:691-700

24. Zhang L, Shi Z, Lang Q (2011) J Solid State Electrochem 15:801809

25. Shieh Y-T, Lu Y-T, Wang T-L, Yang C-H, Lin R-H (2014) J Solid State Electrochem 18:975-984

26. Ti C-C, Kumar SA, Chen S-M (2009) J Solid State Electrochem 13: $397-406$

27. Łuczak T (2008) Electrochim Acta 53:5725-5737

28. Zhang Y, Lin L, Feng Z, Zhou J, Lin Z (2009) Electrochim Acta 55: $265-270$

29. Jin G-P, Lin ĆX-Q, Ding ĆY-F (2006) J Solid State Electrochem 10:987-994

30. Kang J, Zhuo ĆL, Lu ĆX, Wang X (2005) J Solid State Electrochem 9:114-120

31. Majewska UE, Chmurki K, Biesiada K, Olszyna AR, Bilewicz R (2006) Electroanalysis 18:1463-1470

32. Li J, Wu X, Yu Y, Le S (2009) J Solid State Electrochem 13:18111818

33. Malem F, Mandler D (1993) Anal Chem 65:37-41

34. Zhang J, Ojama M (2007) Electrochem Commun 9:459-464

35. Łuczak T, Bełtowska-Brzezinska M (2011) Microchim Acta 174: 19-30

36. Codognoto L, Winter E, Paschoal JAR, Suffredini HB, Cabral MF, Machado SAS, Rath S (2007) Talanta 72:427-433

37. Łuczak T (2014) Electroanalysis 26:2152-2160

38. Xiao Y, Guo C, Li CM, Li Y, Zhang J, Xue R, Zhang S (2007) Anal Biochem 371:229-237

39. Mohadesi A, Karimi MA, Pourfarsi M (2011) Int J Electrochem Sci 6:309-318
40. Zhang L, Jia J, Zou X, Dong S (2006) Electroanalysis 16:14131418

41. Yixin S, Wang SF (2006) Microchim Acta 144:115-121

42. Li B, Ye Q (2014) In: Zhou F (ed) Antifouling surfaces and materials. Springer, Berlin, pp. 31-42

43. Kinge S, Crego-Calama M, Reinhoudt DN (2008) ChemPhysChem 9:20-42

44. Gorczyński A, Pakulski D, Szymańska M, Kubicki M, Bułat K, Łuczak T, Patroniak V (2016) Talanta 149:347-355

45. McMurry J (2005) Organic chemistry. National Scientific Publishers, Warsaw

46. Nowicki W (2002) The behaviour of systems composed of nanosized particles and very-high-molecular weight linear polymers. Adam Mickiewicz University Press, Poznań

47. Clavilier J, Nguyen Van Huong C (1977) J Electroanal Chem 80: 101-114

48. Hamelin A, Vitanov T, Sevastyanov E, Popow A (1983) J Electroana Chem 145:225-264

49. Łuczak T (2005) Collect. Czech. Chem Commun 70:2027-2037

50. Trasatti S, Petrii O (1991) Pure Appl Chem 63:711-734

51. Meier A, Uhlendorf I, Meissner D (1995) Electrochim Acta 40: $1523-1535$

52. Ulman A (1996) Chem Rev 96:1533-1554

53. Paik W-K, Eu S, Lee K, Chon S, Kim M (2000) Langmuir 16: 10198-10205

54. Chon S, Paik W-K (2001) Phys Chem Chem Phys 3:3405-3410

55. Wendland TR, Muntean BS, Kaur J, Mukherjee J, Chenc J, Tan Attygalle XD, Collins RW, Kirchhoff JR, Viranga Tillekeratne LM (2011) Electroanalysis 23:2275-2279

56. Ballarin B, Cassani MC, Scavetta E, Tonelli D (2008) Electrochim Acta 53:8034-8044

57. Manso J, Mena ML, Yăñez-Sedeno P, Pingarron J (2007) J Electroanal Chem 303:1-7

58. Dodero G, De Michieli L, Cavalleri O, Rolandi R, Olivieri L, Dacca A, Parodi R (2000) Coll Surf A 175:121-128

59. Jeyabharathi C, Ahrens P, Hasse U, Scholz F (2016) J Solid State Electrochem. doi:10.1007/s10008-016-3228-1

60. Newman RC, Burstein GT (1981) J Electroanal Chem 129:343438

61. Bard AJ, Faulkner LK (2001) Electrochemical methods: fundamentals and applications. Wiley, New York

62. Liu S-F, Li X-H, Li Y-C, Li Y-F, Li J-R, Jiang L (2005) Electrochim Acta 51:427-431

63. Leopold MC, Black JA, Bowden EF (2002) Langmuir 18:978-980

64. Finot MO, McDermott MT (2000) J Electroanal Chem 488:125132

65. Wang L, Bai J, Huang P, Wang H, Zhang L, Zhao Y (2006) Electrochem Commun 8:1035-1040

66. Hawley MD, Tatawawadi SV, Piekarski S, Adams RN (1967) J Am Chem Soc 89:447-450

67. Kisza A (2001) Electrochemistry II. Technical Scientific Publishers, Warsaw

68. Jia Z, Liu J, Shen Y (2007) Electrochem Commun 9:2739-2743

69. Sellers H, Ulman A, Shnidman Y, Eilers JE (1993) J Am Chem Soc 115:9389-9401

70. Analytical Methods Committee (1987) Analyst 112:199-204 